\title{
O discurso da empregabilidade: o que pensam a academia e o mundo empresarial ${ }^{1}$ The discourse of employability: what academia and the business world think
}

\author{
Diogo Henrique Helal ${ }^{2}$ \\ Maíra Rocha ${ }^{3}$
}

\section{Resumo}

A preocupação com a empregabilidade é resultado das novas exigências feitas aos trabalhadores, por parte das organizações. Sabe-se, contudo, que o entendimento acerca do tema é bastante diverso e controverso. Nesse contexto, este artigo busca entender como o termo tem emergido e ganho força, tanto no meio acadêmico quanto no empresarial. Para isso, foi feita uma pesquisa qualitativa com profissionais e acadêmicos de recursos humanos, em Belo Horizonte-MG, bem como foram analisados dados secundários em publicações acadêmicas e não acadêmicas (empresariais). Os dados coletados foram analisados de modo quantitativo e qualitativo, com base nas técnicas de análise bibliométrica e de análise de conteúdo (AC). Os achados da pesquisa indicam que, em ambos os grupos pesquisados - empresarial e acadêmico das duas concepções acerca do tema, destacadas na teoria, a empresarial-individual (que condiciona a empregabilidade à capacidade da mão-de-obra adaptar-se às novas exigências do mundo do trabalho e das organizações) e a crítica-social (que trata a empregabilidade como um discurso, transferindo a responsabilidade pelo emprego, da sociedade e do Estado para o próprio trabalhador), prevalece a primeira. Diante disso, o artigo traz uma reflexão, buscando indicar à sociedade que o discurso neoliberal da empregabilidade não traz consigo a garantia de empregos e que a busca incessante pelo conhecimento (capital humano) nem sempre é garantia de colocação no mercado de trabalho.

Palavras-chave: empregabilidade; capital humano; mercado de trabalho.

\begin{abstract}
Concern over employability the result of new requirements that organizations make of workers. It is known, however, that the understanding of this concept is somewhat diverse and controversial. In this context, the present article seeks to understand how employability has emerged and gained force in two fields - the academic and the business. Thus, a qualitative study was conducted with professionals and Human Resource academics in Belo Horizonte-MG, together with an analysis of secondary data in academic rather than business publications. The collected data were analyzed quantitatively and qualitatively on the basis of the techniques of bibliometric analysis and content analysis. The findings of the study indicate that in both groups - business and academic - the two conceptions of employability, highlighted in the business-individual theory, which that considers employability as the capacity of the adaptation of man power when facing the new requirements of the world of work and organizations, and the critical-social one, which treats employability as a speech that transfers the responsibility for the job from society and the State to the worker himself were the first to emerge. Thus, the article shows a reflection, seeking to indicate to society that the neoliberal speech concerning employability does not itself bring a guarantee of jobs, and that the unceasing search for knowledge (human capital) does not always guarantee equivalent opportunities in the world of the work.
\end{abstract}

Key words: employability; human capital; labour market.

Artigo submetido em setembro de 2009 e aceito para publicação outubro de 2009

\footnotetext{
${ }^{1}$ Uma versão preliminar deste artigo foi apresentada no XXXII EnANPAD. Este artigo apresenta os resultados parciais do projeto de pesquisa "A construção discursiva dos conceitos de empregabilidade e competencia: diferentes visões e implicações" que teve o auxílio do CNPq e da CAPES.
}

2 Doutor em Ciências Humanas: Sociologia e Política pela Universidade Federal de Minas Gerais/UFMG. Pesquisador da Fundação Joaquim Nabuco/FUNDAJ. Endereço: FUNDAJ/DIPES, Diretoria de Pesquisas Sociais, Rua Dois Irmãos, 92, Apipucos Recife, PE, Brasil, CEP 52071-440. Email: diogo.helal@fundaj.gov.br

3 Graduada em Relações Públicas e Jornalismo pelo Centro Universitário de Belo Horizonte/UNIBH. Assessora de comunicaçã. Endereço: Rua Jacuí, 10, apto 303 BL3, Floresta, Belo Horizonte, MG, Brasil CEP 31110-050. Email: rpmaira@yahoo.com.br 


\section{Introdução}

A palavra "empregabilidade" ocupa posição de destaque na academia, no mundo empresarial e nas discussões sobre políticas públicas, no Brasil e em outros países. Convém destacar, entretanto, que seu surgimento é relativamente recente. Reflete o agravamento da crise pela qual passa o mercado de trabalho em todo mundo, em função da diminuição do número de empregos formais e do aumento dos níveis de desemprego e de trabalho informal.

É sabido que a terceirização e a flexibilização da economia vêm causando fortes impactos no mercado de trabalho em todo o Brasil, que, segundo Pochmann (2001), vive um momento de desestruturação. Para o autor, os novos conhecimentos tecnológicos se associaram às exigências empresariais de contratação de empregados com polivalência multifuncional, maior nível de motivação e habilidades laborais adicionais no exercício do trabalho. Foi esse novo contexto do mercado de trabalho, permeado pelo desemprego e pela dificuldade em se (re)inserir nesse mercado que trouxe o debate acerca da empregabilidade para a ordem do dia, no Brasil e em diversos outros países. Deve ser ressaltado, inclusive, que as novas formas de emprego, tais como as cooperativas de trabalho, não têm garantido a empregabilidade dos indivíduos (PICCININI; OLIVEIRA, 2002).

Vale lembrar, entretanto, que a atual conjuntura do mercado de trabalho é produto do processo de reestruturação econômica iniciado na década de 1970, com o esgotamento do modelo fordista de produção. $\mathrm{Na}$ verdade, a preocupação com a empregabilidade resulta das novas exigências feitas aos trabalhadores, por parte das organizações, sob a égide do novo modo de acumulação capitalista, conhecido como pós-fordismo ou modo de acumulação flexível. As organizações passaram por um processo de reestruturação, no qual várias ocupações foram destruídas e outras surgiram. O emprego industrial foi reduzido em função da alta inserção de tecnologia, enquanto o setor de serviços se expandiu. O mercado de trabalho se flexibilizou e as relações de trabalho se tornaram mais precárias - verificando-se o aumento da ocupação por conta própria e da informalidade, em geral.

\section{Conceitos}

Por se tratar de um fenômeno recente, a conceituação e o entendimento sobre empregabilidade são dispersos e diversificados. Exemplos: $\mathrm{O}$ conceito de empregabilidade tem sido utilizado para referir-se às condições da integração dos sujeitos à realidade atual dos mercados de trabalho e ao poder que possuem de negociar sua própria capacidade de trabalho, considerando o que os empregadores definem por competência. (MACHADO, 1998, p.18)

Para Lavinas (2001, p.03), o uso do termo empregabilidade remete "às características individuais do trabalhador capazes de fazer com que possa escapar do desemprego mantendo sua capacidade de obter um emprego". Na visão da autora, o divisor de águas entre trabalhadores empregáveis e não-empregáveis reside no seu grau de aptidão para um determinado trabalho. Minarelli (1995), por sua vez, entende a empregabilidade como a habilidade de ter emprego.

Nas definições de empregabilidade apresentadas, o termo é visto como a capacidade de adaptação da mão-deobra às novas exigências do mundo do trabalho e das organizações. Entretanto, não há um consenso em relação à conceituação do tema. 
Diversos outros autores referem-se à empregabilidade como um discurso neoliberal, que transfere a responsabilidade pelo emprego da sociedade e do Estado para o próprio trabalhador. Carrieri e Sarsur (2002) entendem a empregabilidade como uma estratégia adotada pela alta administração das empresas, no sentido de transferir para o trabalhador a responsabilidade pela não-contratação ou demissão. Para Rodrigues (1997, p.228), o conceito de empregabilidade, conjugado com outros conceitos mais gerais - como globalização, competitividade e reestruturação industrial - busca consolidar a "construção de uma rede discursivo-conceitual que tenta simultaneamente, por um lado, explicar uma nova etapa do desenvolvimento civilizatório e, por outro lado, facilitar as dores do parto do novo mundo do trabalho".

É possível supor que a ênfase no mercado e no cliente, nas novas competências gerenciais e na empregabilidade resolva um tradicional dilema gerencial, qual seja, o de controlar e direcionar os indivíduos para comportamentos desejados: autonomia, flexibilidade, criatividade, autovigilância, espírito empreendedor etc. Para Freitas (2000, p.11), nesse discurso, e também nas ações organizacionais, é dito que o indivíduo deve considerar-se o "empreendedor de sua própria vida", que ele seja o "seu próprio projeto" e que se veja como "um capital que deve dar retorno", buscando sempre melhorar sua empregabilidade.

No entanto, o acesso ao emprego não pode ser determinado de forma simplista e restrita. A realidade mostra que várias são as explicações e os determinantes da empregabilidade e de suas variantes. Segundo Paiva (2000, p.57), empregabilidade é uma "construção social mais complexa, na medida em que se descola das instituições formais e da experiência adquirida para considerar aspectos pessoais e disposições subjetivas e para dar maior peso não apenas a aspectos técnicos, mas à socialização".

Essa visão quanto ao que seja a empregabilidade é bastante apropriada à realidade brasileira, marcada, segundo Freitas (1997), por um forte traço de personalismo. Para o autor, a sociedade brasileira é baseada em relações pessoais. Nesse sentido, não se pode imaginar que o acesso ao emprego no Brasil ocorra de modo impessoal e meritocrático, valorizando principalmente as variáveis ligadas ao esforço próprio individual, nomeadamente, investimentos em capital humano (educação). Civelli (1998) destaca que o acesso ao mercado de trabalho deve ser estudado de uma perspectiva diferenciada, na qual variáveis simbólicas, culturais, sociais e de valor estão se tornando fundamentais. Essa foi a estratégia proposta por Helal (2005), que explora a temática da empregabilidade individual, procurando ampliar a discussão corrente sobre o assunto, centrada na teoria do capital humano. Nesse sentido, o autor propõe um modelo explicativo da empregabilidade individual, baseado em profunda revisão bibliográfica, com o propósito de buscar melhor entendimento sobre o que determina o acesso ao emprego. O modelo é concebido com base em três abordagens: teoria do capital humano, do capital cultural e do capital social. São apresentadas, ainda, sugestões para a operacionalização das variáveis, tornando o modelo aplicável.

Do debate anteriormente apresentado é possível identificar dois significados para o termo empregabilidade: o empresarial (que considera a empregabilidade como a capacidade de adaptação da mão-de-obra [do indivíduo] às novas exigências do mundo do trabalho e das organizações) e o crítico (que trata a empregabilidade como um discurso, transferindo a responsabilidade pelo emprego da sociedade e do Estado para o próprio trabalhador). ${ }^{4}$

\footnotetext{
${ }^{4}$ O estudo de Dourado e Carvalho (2007) se insere nesse debate, cujo objetivo é identificar e analisar discursos nas organizações e no mercado de trabalho. Especificamente, as autoras desvendaram o discurso de QVT - Qualidade de Vida no Trabalho numa organização em Pernambuco. Os resultados mostram que, na organização estudada, esse discurso se configura como uma maneira eficaz de ocultar a dominação presente na relação trabalhador/empresa, no sentido de conseguir a participação e o comprometimento deste na solução dos efeitos negativos acumulados no desempenho de suas funções.
} 
De acordo com Nader e Oliveira (2007, p.4), a noção de empregabilidade que ganha espaço atualmente "é aquela que localiza no próprio trabalhador a tarefa de se ajustar às condições de trabalho". Ainda segundo as autoras (Ibidem, p.4):

[...] tanto a literatura de gestão e revistas de maior alcance (como Você S/A e Exame) como as políticas públicas ligadas à questão do emprego dão grande ênfase ao aprimoramento do trabalhador para que este se torne atraente ao mercado de trabalho e lá garanta o seu espaço.

A ênfase no indivíduo é clara no primeiro significado. Nele, a empregabilidade é totalmente dependente da capacidade individual de se adaptar às demandas do mercado de trabalho.

O segundo significado do termo busca identificar exatamente a limitação de se tratar a empregabilidade como algo restrito ao esforço individual. Essa segunda perspectiva busca contextualizar socialmente a busca pelo emprego, atribuindo responsabilidade a fatores presentes na sociedade. Tal questão insere-se no debate da sociologia econômica sobre a natureza inserida (embedded nature) do processo econômico, como bem destaca Granovetter (1985). Segundo o autor, a ação econômica - nesse caso, a busca e o processo de seleção para um emprego - deve ser vista e estudada como algo influenciado pela estrutura social na qual se insere, ou seja, é influenciada não apenas por características do indivíduo (estoque de capital humano), mas também por elementos inerentes ao contexto familiar e social. É importante destacar que tal perspectiva supera o foco tradicional na estrutura e em elementos técnicos, enfatizando o aspecto dinâmico dos relacionamentos interpessoais.

Essa divisão quanto ao entendimento do que seja empregabilidade em duas perspectivas - empresarialindividual e crítica-social - é a adotada por Gazier (2001). A primeira perspectiva se refere à noção de empregabilidade de iniciativa e a segunda, à noção de empregabilidade interativa.

Recentes estudos têm fundamentado esse entendimento de que a empregabilidade deve ser vista como algo que depende não apenas do esforço individual, mas também de fatores presentes no contexto social. Por exemplo, Helal, Neves e Fernandes (2007) analisam as alterações dos efeitos do capital cultural, do capital social e do capital humano na empregabilidade gerencial no Brasil. Os resultados do estudo desses autores indicam o quanto a associação entre esses três tipos de capital determina as chances de se obter um cargo gerencial no país.

Apesar dos resultados de pesquisa indicarem que no país o acesso a empregos formais tem sido também determinado pelo contexto social no qual o indivíduo se insere, o entendimento acerca do tema que mais tem sido difundido é o individual. A mídia de negócios (e a geral também) vem insistindo na ideia da necessidade do indivíduo se atualizar e ser competente para garantir uma melhor inserção no mercado de trabalho. De acordo com Zulauf (2006), o mercado e os ambientes de trabalho pressionam cada vez mais o ensino superior para que este desenvolva a empregabilidade dos estudantes e atribua a essa habilidade maior relevância nas grades curriculares, instruindo os alunos não apenas do ponto de vista acadêmico, mas também da perspectiva das reais necessidades dos empregadores.

A autora diz que o governo comunga da mesma opinião do mercado, já tendo incentivado algumas universidades a reformar suas grades curriculares. Em níveis variados de aceitação e resistência, o tradicional currículo com enfoque na disciplina está cedendo lugar a uma educação que oferece embasamento acadêmico com habilidades de empregabilidade (ZULAUF, 2006). 
Shiroma e Campos (1997) complementam o raciocínio de Zulauf (2006) e questionam se a função da escola é auxiliar na formação para o trabalho ou se esta ocorre independentemente daquela. Os autores, desse modo, ficam por entender se a escola promove a formação para o indivíduo ou para o mercado de trabalho. A quem a educação atenderia nos tempos de hoje: ao mercado ou ao trabalhador? - questionam Shiroma e Campos (1997). Segundo eles, embora nesse debate não haja convergência de opiniões, estas acabam concorrendo ao mostrar que o aumento da demanda empresarial por trabalhadores com nível mais elevado de escolaridade nem sempre é compatível com as características das atividades desenvolvidas e que nem todos os postos de trabalho requerem essa maior escolaridade. Shiroma e Campos (1997) pontuam, desse modo, um antagonismo advindo da alta especialização: se as pessoas atingem uma capacitação intelectual maior do que a exigida para os cargos, porque os empresários clamam por educação, apontando-a como a principal alavanca para a produtividade e a qualidade?

Rummert e Ventura (2007) concluem que, de forma geral:

[...] as políticas educativas com caráter compensatório e aligeirado reiteram, a partir de reordenamentos econômicos dos quais derivam o desemprego estrutural e novas formulações ideológicas centradas no empreendedorismo e na empregabilidade, a subalternidade das propostas de educação para a classe trabalhadora. (RUMMERT; VENTURA, 2007, p.29)

Diante de tal debate, este estudo pretende entender como o termo empregabilidade tem emergido e ganho força nos meios acadêmico e empresarial. Nessa análise, busca-se observar qual dos dois entendimentos sobre empregabilidade (o empresarial-individual ou o crítico-social) prevalece nos grupos pesquisados.

\section{Metodologia}

Este estudo descreve e analisa as concepções sobre empregabilidade e seus determinantes, em dois grupos: o empresarial e o acadêmico. Em função da profundidade do escopo desta pesquisa, esta foi classificada como qualitativa, que trabalha com um:

universo de significados, motivos, aspirações, crenças, valores e atitudes, o que corresponde a um espaço mais profundo das relações dos processos e dos fenômenos que não podem ser reduzidos à operacionalização de variáveis. (DESLANDES; CRUZ NETO; GOMES, 1997, p.22)

A partir da pesquisa qualitativa, portanto, foi possível levantar as informações necessárias para descrever e analisar as concepções sobre empregabilidade e seus determinantes nos dois grupos estudados.

Os dados de ambos os grupos pesquisados são primários e secundários. Os primários foram coletados por meio de entrevistas em profundidade, aplicadas em sujeitos dos dois grupos de interesse deste estudo. As entrevistas foram realizadas face a face, com apoio de um roteiro contendo sete perguntas norteadoras. Tais entrevistas foram gravadas e posteriormente transcritas, para realização da análise de conteúdo.

Os dados primários do grupo empresarial foram obtidos através de entrevistas com três profissionais: um é responsável pelo setor de recursos humanos de uma organização de médio porte do setor de supermercados, em Belo Horizonte, e dois são funcionários contratados que cursaram até o ensino médio. Por sua vez, no âmbito acadêmico, foram entrevistadas quatro pessoas: duas professoras da área de recursos humanos do curso de 
administração de um IES particular, também de Belo Horizonte, e dois estudantes da mesma instituição cursando os últimos períodos, do mesmo curso.

Os dados secundários desta pesquisa referem-se a artigos de publicações acadêmicas e não-acadêmicas selecionadas para o estudo. No âmbito empresarial, foram selecionadas duas publicações impressas, a revista Você S/A e o jornal Folha de São Paulo, de onde foram escolhidos artigos e matérias sobre empregabilidade que saíram entre janeiro de 2005 e julho de 2007. A escolha desse período foi determinada em função da quantidade de material obtido. A consulta e a seleção de artigos e matérias foram feitas no site <www.uol.com.br>, por meio de senha e acesso à página de pesquisa de material publicado de cada publicação.

No âmbito acadêmico, foram pesquisadas publicações da área, como a RAC - Revista de Administração Contemporânea e os periódicos residentes no portal Scielo, além de anais dos encontros da Anpad, que tratassem da temática da empregabilidade no período de janeiro de 1997 a julho de 2007. Tal pesquisa foi feita no site <www.anpad.org.br>, por meio de senha e acesso à página de pesquisa de publicações.

Os dados primários foram submetidos à análise de conteúdo e os secundários, às análises de conteúdo e bibliométrica. Bardin (1977, p.42) define análise de conteúdo como:

[...] um conjunto de técnicas de análise das comunicações visando obter, por procedimentos sistemáticos e objetivos de descrição do conteúdo das mensagens, indicadores (quantitativos ou não) que permitam a inferência de conhecimentos relativos às condições de produção/recepção (variáveis inferidas) destas mensagens.

Nesse sentido, foram estabelecidas e identificadas as unidades de análise, a grade de análise, as categorias, a presença e a ausência de elementos, bem como sua frequência e relevância.

É oportuno destacar que associada à metodologia proposta, este estudo adotou a estratégia da triangulação, proposta por Denzin (1978) e rediscutida por Flick (1992). Tal estratégia pressupõe que os métodos e as técnicas de pesquisa podem ser vistos como complementares, ao invés de rivais. A triangulação foi de dados, uma vez que se pretendeu usar diferentes fontes de dados. O fenômeno "empregabilidade" foi estudado a partir de diferentes momentos (tempo), locais (espaço) e pessoas (informantes).

Além disso, a pesquisa bibliométrica foi outra forma de análise utilizada neste estudo, com o propósito de se ter mais uma possibilidade de confrontar os discursos dos diferentes meios de comunicação selecionados (acadêmicos e não-acadêmicos) acerca da temática em questão.

Antes de pontuar os dados encontrados nas pesquisas bibliométrica e qualitativa, é necessário definir os conceitos-chave utilizados como parâmetros de análise. Na pesquisa bibliométrica, os artigos foram divididos com base no seguinte critério:

Estuda empregabilidade $x$ apenas cita ou comenta brevemente a empregabilidade: o primeiro critério abarca todos os artigos, acadêmicos ou massivos que se dispuseram a tecer um discurso e uma análise mais acurada e profunda sobre a temática da empregabilidade. Já o segundo critério representa aqueles artigos nos quais a empregabilidade é apenas aludida e não explorada com finura suficiente. Assim, apenas os artigos que estudaram a temática foram selecionados para o estudo. 
Tanto os artigos selecionados que estudaram a empregabilidade quanto o conteúdo das entrevistas realizadas foram analisados tomando-se por parâmetro as seguintes categorias de análise, referentes aos entendimentos sobre o tema verificados no debate teórico: visão crítica-social e visão empresarial-individual. $O$ primeiro entendimento acerca da empregabilidade representa o conceito de Carrieri e Sarsur (2002), que trata a empregabilidade como um discurso neoliberal que transfere a responsabilidade do emprego da sociedade, da academia e do Estado, unicamente, para o indivíduo. A visão empresarial, por sua vez, representa a visão mercadológica e individual, presente em Minarelli (1995) e em Lavinas (2001), por exemplo, que defendem que a obtenção e a manutenção do emprego advêm unicamente de características individuais, como capital humano, por exemplo.

\section{Apresentação dos dados e análise}

Dados bibliométricos do grupo empresarial x grupo acadêmico nas publicações impressas

Tabela 1 - Quantidade de artigos selecionados para análise

\begin{tabular}{|l|l|l|l|l|l|}
\hline \multirow{2}{*}{ Critério } & \multicolumn{2}{|l|}{ GRUPO ACADÊMICO*1 } & \multicolumn{3}{l|}{ GRUPO EMPRESARIAL*2 } \\
\cline { 2 - 6 } & $\begin{array}{l}\text { Artigos obtidos } \\
\text { no Scielo }\end{array}$ & $\begin{array}{l}\text { RAC } \\
\text { Enanpads }\end{array}$ & $\begin{array}{l}\text { Você } \\
\text { S/A }\end{array}$ & $\begin{array}{l}\text { Folha de São } \\
\text { Paulo }\end{array}$ \\
\hline Estuda a empregabilidade & 4 & 15 & 5 & 21 & \\
\hline Apenas cita & 2 & 10 & 6 & 45 & \\
\hline TOTAL & 6 & 25 & 11 & 66 \\
\hline
\end{tabular}

*1 No período de janeiro de 1997 a julho de 2007;

*2 No período de 2005 a julho de 2007.

Fonte: dados da pesquisa.

Foram selecionados para a análise apenas os artigos com maior nível de aprofundamento na abordagem da empregabilidade. Feita a seleção, o universo pesquisado resultou num total de 45 artigos, sendo 19 acadêmicos e 26 não-acadêmicos.

É perceptível a predominância de estudos "críticos" sobre o tema em questão nos artigos do grupo acadêmico. Entretanto, é necessário destacar na Folha de São Paulo, jornal bem conceituado e bastante lido no Brasil, uma maioria de textos críticos, durante o período analisado. Tal fato mostra que algumas publicações de massa começam a se preocupar em ter uma postura mais crítica diante do Estado, das instituições acadêmicas e da própria sociedade. 
Tabela 2 -Visões acerca do tema nas publicações de ambos os grupos

\begin{tabular}{|l|l|l|l|l|}
\hline \multirow{2}{*}{$\begin{array}{c}\text { Estuda a } \\
\text { empregabilidade }\end{array}$} & \multicolumn{2}{|c|}{ GRUPO ACADÊMICO } & \multicolumn{2}{c|}{ GRUPO EMPRESARIAL } \\
\cline { 2 - 7 } & $\begin{array}{c}\text { RAC e } \\
\text { Enanpads }\end{array}$ & $\begin{array}{c}\text { Periódicos no } \\
\text { Scielo }\end{array}$ & Você S/A & $\begin{array}{c}\text { Folha de São } \\
\text { Paulo }\end{array}$ \\
\hline Visão crítica & 9 & 4 & 0 & 13 \\
\hline Visão empresarial & 4 & 0 & 5 & 8 \\
\hline Visão híbrida & 2 & 0 & 0 & 0 \\
\hline TOTAL & 15 & 4 & 5 & 21 \\
\hline
\end{tabular}

Fonte: dados da pesquisa.

Em outra tabela pode-se fazer a comparação dos anos em que essas mensagens foram veiculadas. A tabela 3 representa frequência de artigos que estudam empregabilidade, no período estudado:

Tabela 3 - Publicações acadêmicas classificadas por períodos

\begin{tabular}{|l|l|l|l|l|l|l|l|l|}
\hline \multirow{2}{*}{\begin{tabular}{l} 
Estuda $\begin{array}{l}\text { a } \\
\text { empregabilidade } \\
\text { anos pesquisados }\end{array}$ \\
\cline { 3 - 11 }
\end{tabular}} & $\begin{array}{l}\text { RAC } \\
\text { Enanpads }\end{array}$ & C & E & H & $\begin{array}{l}\text { Periódicos } \\
\text { no Scielo }\end{array}$ & C & E & H \\
\hline 2006 & 2 & 2 & 0 & 0 & 1 & 1 & 0 & 0 \\
\hline 2005 & 3 & 3 & 0 & 0 & 1 & 1 & 0 & 0 \\
\hline 2004 & 0 & 0 & 0 & 0 & 0 & 0 & 0 & 0 \\
\hline 2003 & 5 & 3 & 2 & 0 & 0 & 0 & 0 & 0 \\
\hline 2002 & 1 & 0 & 1 & 0 & 0 & 0 & 0 & 0 \\
\hline 2001 & 1 & 1 & 0 & 0 & 0 & 0 & 0 & 0 \\
\hline 2000 & 1 & 0 & 0 & 1 & 0 & 0 & 0 & 0 \\
\hline 1999 & 0 & 0 & 0 & 0 & 1 & 1 & 0 & 0 \\
\hline 1998 & 0 & 0 & 0 & 0 & 0 & 0 & 0 & 0 \\
\hline 1997 & 1 & 0 & 1 & 0 & 0 & 0 & 0 & 0 \\
\hline TOTAL & 1 & 0 & 0 & 1 & 1 & 1 & 0 & 0 \\
\hline
\end{tabular}

Legenda: $\mathrm{C}=$ crítica, $\mathrm{E}=$ empresarial, $\mathrm{H}$ = híbrida.

Fonte: dados da pesquisa.

Os dados da tabela 3 reforçam o entendimento de que a preocupação em estudar a empregabilidade é recente. A maior parte dos estudos acadêmicos sobre o tema, nos periódicos e anais de eventos estudados, está concentrada no período a partir de 2004.

Já a tabela 4 resume a frequência de artigos veiculados nas publicações empresariais, que se aprofundaram no estudo do fenômeno, a partir da ocorrência das subcategorias criadas por este estudo. 
Tabela 4 - Publicações empresariais classificadas por períodos

\begin{tabular}{|l|l|l|l|l|l|l|l|l|l|}
\hline \multirow{2}{*}{\begin{tabular}{l} 
Estuda $\begin{array}{l}\text { a } \\
\text { empregabilidade } \\
\text { anos pesquisados }\end{array}$ \\
\cline { 2 - 12 }
\end{tabular}} & $\begin{array}{l}\text { Golha de São } \\
\text { Paulo }\end{array}$ & C & E & H & $\begin{array}{l}\text { Você } \\
\text { S/A }\end{array}$ & C & E & H \\
\hline 2007 (até julho) & 4 & 3 & 1 & 0 & 2 & 0 & 2 & 0 \\
\hline 2006 & 8 & 6 & 2 & 0 & 2 & 0 & 2 & 0 \\
\hline 2005 & 4 & 1 & 3 & 0 & 1 & 0 & 1 & 0 \\
\hline TOTAL & 16 & 10 & 6 & 0 & 5 & 0 & 5 & 0 \\
\hline
\end{tabular}

Legenda: $\mathrm{C}=$ crítica, $\mathrm{E}=$ empresarial, $\mathrm{H}$ = híbrida.

Fonte: dados da pesquisa.

Nessa tabela é necessário ressaltar, prioritariamente, a disparidade dos resultados encontrados nos meios de comunicação de massa. As revistas especializadas em mercado e carreira, aqui representadas pela Você S/A, têm uma visão completamente empresarial sobre a empregabilidade, enquanto a Folha de São Paulo caminha para um pensamento mais crítico e consciente.

Dados comparativos do grupo empresarial $\mathrm{x}$ grupo acadêmico nas pesquisas qualitativas por entrevistas em profundidade

A fim de organizar e melhorar a exposição dos resultados das entrevistas qualitativas, os dados foram distribuídos em tabelas. Buscou-se apenas classificar o conteúdo das respostas a cada pergunta, segundo as concepções acerca do tema - visão crítica e empresarial. Não se pretende aqui descartar as falas dos entrevistados, que serão usadas nas considerações finais para justificar os índices expostos. As tabelas 5, 6, 7 e 8 têm por objetivo tornar claro qual grupo fez mais referências às visões "crítica" e "empresarial" sobre empregabilidade. Os resultados aqui apresentados representam a análise dos pesquisadores sobre o discurso suscitado a cada pergunta formulada durante as entrevistas.

Tabela5 - Grupo acadêmico - entrevistas com professores

\begin{tabular}{|c|c|c|c|c|c|c|c|c|c|c|c|c|c|c|}
\hline \multirow{4}{*}{ CATEGORIAS } & \multicolumn{14}{|c|}{ GRUPO ACADÊMICO } \\
\hline & \multicolumn{7}{|c|}{ Professores A } & \multicolumn{7}{|c|}{ Professores B } \\
\hline & \multicolumn{7}{|c|}{ Perguntas } & \multicolumn{7}{|c|}{ Perguntas } \\
\hline & 1 & 2 & 3 & 4 & 5 & 6 & 7 & 1 & 2 & 3 & 4 & 5 & 6 & 7 \\
\hline Crítica & & & & & & & & & & & $\mathrm{x}$ & & & \\
\hline Empresarial & $\mathrm{x}$ & $\mathrm{x}$ & & & & & & $\mathrm{x}$ & & $\mathrm{X}$ & & $\mathrm{x}$ & & $\mathrm{x}$ \\
\hline Híbrida & & & $\mathrm{x}$ & $\mathrm{X}$ & $\mathrm{x}$ & $\mathrm{X}$ & $\mathrm{x}$ & & $\mathrm{x}$ & & & & $\mathrm{x}$ & \\
\hline
\end{tabular}

Fonte: dados da pesquisa

Como se pode perceber na tabela 5, a visão dos professores entrevistados sobre empregabilidade é híbrida. Entretanto, numa análise individualizada, é possível observar que o professor $\mathrm{B}$ tem uma visão 
predominantemente "empresarial", o que pode indicar que, mesmo tratando-se de professores ligados à área de recursos humanos, o entendimento dominante sobre o que seja empregabilidade não é o crítico.

A opinião dos alunos entrevistados também reforça a impressão de que a visão crítica sobre empregabilidade é pouco presente na academia.

É importante lembrar que os resultados da análise bibliométrica dos dados secundários obtidos no meio acadêmico não indicam uma predominância da visão empresarial. Essa diferença encontrada nos resultados pode indicar uma dissociação entre o que se pensa e se publica sobre o assunto e o que é ensinado aos alunos. Também pode ser observado que, numa comparação com as respostas de professores e alunos, é bem menor a incidência do entendimento híbrido sobre empregabilidade nas publicações acadêmicas.

Tabela 6 - Grupo acadêmico - entrevistas com alunos

\begin{tabular}{|c|c|c|c|c|c|c|c|c|c|c|c|c|c|c|}
\hline \multirow{4}{*}{ CATEGORIAS } & \multicolumn{14}{|c|}{ GRUPO ACADÊMICO } \\
\hline & \multicolumn{7}{|c|}{ Aluno A } & \multicolumn{7}{|c|}{ Aluno B } \\
\hline & \multicolumn{7}{|c|}{ Perguntas } & \multicolumn{7}{|c|}{ Perguntas } \\
\hline & 1 & 2 & 3 & 4 & 5 & $\overline{6}$ & 7 & 1 & 2 & 3 & 4 & 5 & $\overline{6}$ & 7 \\
\hline \multicolumn{15}{|l|}{ Crítica } \\
\hline Empresarial & $\mathrm{x}$ & & $\mathrm{x}$ & & $\mathrm{x}$ & $\mathrm{x}$ & $\mathrm{x}$ & $\mathrm{X}$ & & & $\mathrm{x}$ & & & $\mathrm{x}$ \\
\hline Híbrida & & $\mathrm{x}$ & & $\mathrm{x}$ & & & & & $\mathrm{x}$ & $\mathrm{x}$ & & $\mathrm{x}$ & $\mathrm{X}$ & \\
\hline
\end{tabular}

Fonte: dados da pesquisa.

Tabela 7 - Grupo empresarial e entrevistas com funcionários de nível médio

\begin{tabular}{|c|c|c|c|c|c|c|c|c|c|c|c|c|c|c|}
\hline \multirow{4}{*}{ CATEGORIAS } & \multicolumn{14}{|c|}{ GRUPO EMPRESARIAL } \\
\hline & \multicolumn{7}{|c|}{ Funcionário (ensino médio) A } & \multicolumn{7}{|c|}{ Funcionário (ensino médio) B } \\
\hline & \multicolumn{7}{|c|}{ Perguntas Questionário } & \multicolumn{7}{|c|}{ Perguntas Questionário } \\
\hline & 1 & 2 & 3 & 4 & 5 & 6 & 7 & 1 & 2 & 3 & 4 & 5 & 6 & 7 \\
\hline \multicolumn{15}{|l|}{ Crítica } \\
\hline Empresarial & & & $\mathrm{x}$ & & & $\mathrm{X}$ & $\mathrm{x}$ & $X$ & & $\mathrm{x}$ & $\mathrm{x}$ & $\mathrm{x}$ & $\mathrm{X}$ & \\
\hline Híbrida & $\mathrm{x}$ & $x$ & & $\mathrm{x}$ & $\mathrm{x}$ & & & & $\mathrm{x}$ & & & & & $x$ \\
\hline
\end{tabular}

Fonte: dados da pesquisa. 
Tabela 8 - Grupo empresarial e entrevista com o profissional de $R H$

\begin{tabular}{|c|c|c|c|c|c|c|c|}
\hline \multirow{4}{*}{ CATEGORIAS } & \multicolumn{7}{|c|}{ GRUPO EMPRESARIAL } \\
\hline & \multicolumn{7}{|c|}{ RH } \\
\hline & \multicolumn{7}{|c|}{ Perguntas } \\
\hline & 1 & 2 & 3 & 4 & 5 & 6 & 7 \\
\hline \multicolumn{8}{|l|}{ Crítica } \\
\hline Empresarial & & & $\mathrm{x}$ & $\mathrm{X}$ & $\mathrm{x}$ & & $\mathrm{x}$ \\
\hline Híbrida & $\mathrm{x}$ & $\mathrm{x}$ & & & & $\mathrm{x}$ & \\
\hline
\end{tabular}

Fonte: dados da pesquisa.

Os resultados das entrevistas realizadas no grupo empresarial indicam uma acentuada predominância do entendimento de que a empregabilidade é um atributo individual. Percebe-se que os funcionários são pouco críticos, além de contaminados pelo discurso dominante, uma vez que pensam a empregabilidade como encargo exclusivo do indivíduo, eximindo o Estado, a academia e a sociedade de qualquer responsabilidade. Ainda que a visão empresarial prevaleça, nota-se que no universo empresarial pesquisado o entendimento sobre empregabilidade não é tão "sólido". Mesmo tendo sido constatada a falta de percepções críticas sobre o tema, algumas respostas foram classificadas como híbridas, denotando o ponto de vista de que a responsabilidade pelo emprego também recai em outras esferas que não apenas a individual.

\section{Análise dos dados}

Ao confrontar os dados da pesquisa qualitativa com os da bibliométrica, pode-se perceber que o conceito de empregabilidade estudado indica que, para os grupos analisados, o fenômeno está em construção e em conflito, já que se encontra pressionado pelas visões empresarial e crítica. No esquema apresentado a seguir podemos observar como a opinião híbrida revela a visão intermediária do fenômeno:

Empresarial-Individual <-------- > Híbrida <----------> Crítica-Social

Entretanto, a temática ainda é majoritariamente vista da perspectiva individual, tanto no grupo acadêmico quanto no empresarial. Foi constatado também que o meio acadêmico tem uma visão crítica "contaminada" a respeito da realidade do mercado, ao contrário do que se verificou nos periódicos de educação pesquisados no Scielo. Nestes, a visão crítica se fez presente mais vezes.

O discurso de um dos professores, o B, (entrevistado 2), confirma a tendência da linha híbrida do grupo acadêmico quando questionado sobre o que a organização deve fazer para manter os indivíduos na organização: "Ela [a organização] deve cuidar da atração, do desenvolvimento e da retenção dessas pessoas, e o indivíduo manter-se uma pessoa interessante. Ele [o indivíduo] não pode cansar de aprender". Entretanto, mais adiante, na mesma entrevista, esse docente define empregabilidade como "a capacidade que o indivíduo tem de se tornar empregável. Ter competências suficientes para permanecer no mercado de trabalho, aproveitando as oportunidades". Ele completa seu raciocínio dizendo que as características para um funcionário ser contratado devem ser "baseadas em atitudes que ELE deve ter" e que o mais importante é "A PESSOA QUERER adquirir conhecimento". 
Assim, apesar de acreditar que a empresa tem papel na empregabilidade individual, o entrevistado atribui a forte responsabilidade pela busca do emprego ao indivíduo.

O outro docente, contudo, apresentou uma posição mais crítica. Segundo este entrevistado, o acesso do trabalhador ao emprego não depende estritamente da sua vontade.

A qualificação não garante emprego; ela é condição necessária. É um conjunto. A escola que tenha boas parcerias e tenha interesse em apresentar esses alunos. Me preocupa quando coloca toda responsabilidade no indivíduo, se a escola não fizer a parte dela, se as empresas não fizerem a parte delas, se o Estado não fizer a dele. $\mathrm{O}$ capitalismo não tem espaço para todo mundo.

Os alunos ouvidos, de forma geral, manifestaram uma opinião empresarial sobre o conceito, embora esse entendimento não seja homogêneo. Para eles, a responsabilidade por manter a empregabilidade do indivíduo também deve ser compartilhada pela empresa:

Tanto [...] profissionalmente quanto pessoalmente [o indivíduo] tem que estar empenhado em melhorar, e a empresa também tem que fornecer recursos para que esse indivíduo tenha também uma autoestima [e consiga] o que ele quer em termos pessoais e profissionais. (aluno B)

No que tange ao grupo empresarial, em que foram entrevistados dois funcionários sem nível superior e um profissional de $\mathrm{RH}$, nota-se uma postura pouco crítica e uma forte presença do discurso dominante, individual, sobre a empregabilidade.

Ele [o indivíduo] tem que ser mais criativo. Procurar ajudar... Aí, outro dia, eu li sobre isso... Até vi no Fantástico... daquele Gehringer lá... [o consultor e comentarista Max Gehringer] Como é que é a palavra lá?... Ele tem que... se reciclar, né? (funcionário A).

O mesmo entrevistado diz que o acesso ao emprego depende exclusivamente da vontade do trabalhador. "Acho que tem que procurar, correr atrás, né? Tem que correr atrás, mesmo. Se não se esforçar, não consegue nada. Procurando cursos, saber mais, ler".

Nota-se, a partir da fala desse entrevistado, o papel da mídia de massa - no caso, a TV Globo - na construção do entendimento sobre o assunto e o mercado de trabalho em geral. É possível perceber que o entrevistado atribui autoridade ao argumento de um jornalista.

A visão tendenciosamente empresarial observada nos entrevistados do grupo acadêmico não reflete a visão crítica, bastante marcante nos artigos publicados; principalmente, nas revistas de educação. Entretanto, no que se refere o grupo empresarial, percebe-se a prevalência da visão individual tanto nas entrevistas com os funcionários e o profissional de RH quanto nas publicações massivas.

No que diz respeito ao que determina e influencia a empregabilidade dos indivíduos, pode-se dizer que houve uma igualdade de opiniões, tanto do meio acadêmico, quanto do meio empresarial. Boa vontade, capacidade de aprender, qualificação para o cargo e autoconfiança foram as qualidades mais citadas pelos entrevistados quando questionados sobre as características que um funcionário deve ter para ser contratado. Destaque-se, ainda, a opinião do profissional de RH sobre o assunto: "eu acho que boa aparência e defesa da empresa em que trabalha ajudam a pessoa a se manter empregada". 
De forma geral, pode-se inferir com este estudo, que a empregabilidade é pensada da mesma forma, tanto em nível acadêmico quanto em nível empresarial. Apesar dos meios acadêmicos ainda continuarem a escrever de forma crítica, a visão dos alunos e dos professores entrevistados não é semelhante, na sua expressão geral. Desse modo, pode-se inferir que a visão empresarial, que domina os meios de comunicação de massa, acaba influenciando e contaminando, não só o grupo empresarial, mas o grupo acadêmico também.

Assim, para a maioria dos entrevistados, a responsabilidade pelo emprego em cada uma das instituições (escola e empresa) é transferida para o indivíduo, que deve se ocupar em trabalhar seu capital humano, suas competências e habilidades pessoais para conseguir pleitear uma fatia do mercado de trabalho.

Entretanto, apesar de jogarem a responsabilidade do emprego para o indivíduo, a maioria dos entrevistados também reconhece que mesmo este estando capacitado, ainda existe grandes chances de que fique desempregado.

Em relação às características que um funcionário deve ter para entrar no mercado de trabalho, pode-se inferir que alunos, professores e funcionários acertaram. As empresas confirmaram que precisam de "funcionários capacitados", dispostos a "aprender sempre" e que "tragam novidades" para elas. Contudo, há um ponto divergente: "defender a empresa", atributo considerado pelo profissional de $\mathrm{RH}$, não estava entre as respostas levantadas por professores, alunos ou funcionários.

\section{Conclusões e recomendações}

Apesar de não ter a pretensão de esgotar o tema ou de sugerir modelos inflexíveis, esse artigo buscou ampliar a debate sobre o discurso da empregabilidade no Brasil. Ao confrontar os dados da pesquisa qualitativa com a pesquisa bibliométrica, pode-se perceber que o conceito de empregabilidade, tanto no âmbito acadêmico quanto no empresarial, não está delineado de forma "pura", observando-se influências ora "críticas-sociais", ora "empresariais-individuais" nos discursos dos entrevistados. Essa descoberta indica que o fenômeno ainda está em construção e em conflito para os grupos analisados, já que se encontra pressionado pelas duas visões apresentadas nesse artigo.

Apesar da análise dos dados indicar que se têm atribuído responsabilidade à sociedade pela obtenção de emprego, o discurso marcadamente dominante é o empresarial-individual. $\mathrm{O}$ discurso que transfere a responsabilidade pelo emprego da sociedade e do Estado para o próprio trabalhador é o comumente adotado pelos grupos mencionados, cabendo, entretanto, ressaltar que no meio acadêmico ainda foram detectados esforços de artigos redigidos sob o enfoque crítico do fenômeno. Contudo, foi observado que o esforço acadêmico em discutir o fenômeno de modo ampliado é maior em suas publicações do que na percepção dos docentes entrevistados. Para a maioria deles, a responsabilidade pelo emprego em cada uma das instituições (escola e empresa) é transferida para o indivíduo, que deve se ocupar em trabalhar seu capital humano, suas competências e habilidades pessoais para conseguir pleitear uma fatia do mercado de trabalho.

O que se percebe, na verdade, é a institucionalização do discurso empresarial-individual da empregabilidade. As profundas reestruturações organizacionais, a prática gerencial, a mídia e a própria academia têm divulgado e reforçado a responsabilidade do indivíduo no processo de obtenção de emprego. Para Gomes (2002, p.53), essa visão de empregabilidade: 
[...] se ergue como uma alternativa de reencaixe poderosa diante da desestruturação que não é só econômica (a flexibilização das relações de trabalho, o desemprego), mas que se imbrica também em conteúdos culturais (a exigência de uma flexibilização da subjetividade) e políticos (o retorno à responsabilidade individual no contrato social do discurso liberal).

É oportuno destacar que a propagação e a força do discurso individual da empregabilidade estão intimamente imbricadas com a promessa falaciosa da teoria do capital humano, inserida na abordagem econômica neoclássica (BECKER, 1964; MINCER, 1974; SCHULTZ, 1961, 1973). Para seus teóricos, quanto maior o estoque de capital humano de um indivíduo, maior sua produtividade marginal e mais elevado será seu valor econômico no mercado de trabalho. Consideramos tal teoria falaciosa, por trazer a promessa de retorno aos investimentos em capital humano. Cardoso (2000, p.9) também identifica essa falácia. Segundo o autor,

tal teoria não dá conta desse fato corriqueiro de que a economia pode não gerar postos de trabalho adequados às qualificações presentes; ou de que pode não gerar postos de trabalho de qualquer natureza. Mais do que isso, não há nada que garanta que o ritmo de investimento das pessoas e famílias em sua qualificação equivalerá ao da criação de postos de trabalho a ela adequados (CARDOSO, 2000, p.9).

Thurow (1977) também critica o argumento da teoria do capital humano. Para o autor, no mercado de trabalho há filas: de trabalhadores e do trabalho em si (labor queue). O matching process ocorre por meio da combinação das duas: os trabalhadores ficam posicionados com base em seus custos de treinamento (treinabilidade), sendo assim selecionados para ocuparem os cargos. Como há assimetria de informação no mercado de trabalho, e como o custo de se observar a "treinabilidade" de todos os possíveis candidatos é alta, os empregadores utilizam as características do background do indivíduo que possam estimar o custo do treinamento. Dessas características, a principal é a educação (vista como uma forma de treinamento).

Outro ponto relevante desse modelo de competição por cargos reside no fato dele dar conta da posição relativa dos trabalhadores em relação às características do background. Como visto, para os economistas neoclássicos, investimentos em capital humano asseguram maior retorno no mercado de trabalho. Para Thurow (1977), tal retorno está condicionado à posição relativa do trabalhador na fila, ou seja, depende das características de background dos outros indivíduos na fila, além de depender das características do cargo, conforme já destacado. Tal visão derruba a noção empresarial-individual acerca da empregabilidade. $\mathrm{O}$ caso brasileiro, por exemplo, tem mostrado que a estrutura ocupacional não acompanhou a ampliação educacional dos trabalhadores ocorrida nos últimos anos - não foram criados cargos suficientes que demandassem maior escolaridade. Essa ampliação do nível educacional também não garantiu o retorno esperado, pois ocorreu para a fila de trabalhadores como um todo. A formação em administração é um bom exemplo para se analisar o matching process no mercado de trabalho. Atualmente, em Belo Horizonte, existem cerca de 60 cursos de bacharelado em administração. Em 1998, esse número não chegava a 10. É nítido que as oportunidades no mercado de trabalho na cidade não cresceram na mesma proporção. $\mathrm{O}$ fato dessa ampliação ter ocorrido em apenas um lado da fila (a dos trabalhadores) tem gerado, além da maior dificuldade na busca por empregos, mesmo após a obtenção do título universitário, uma redução na qualidade das ocupações obtidas pelos recémadministradores. Por exemplo, em seleções para o cargo de operador de telemarketing, tem sido observada a exigência de que o candidato esteja, ao menos, cursando o nível superior.

É imperativo, portanto, mostrar à sociedade que o discurso neoliberal da empregabilidade não gera empregos e que a busca incessante pelo conhecimento nem sempre garantirá a tão sonhada vaga no mundo do trabalho. 


\section{Referências}

BARDIN, Laurence. Análise do conteúdo. Lisboa: Edições 70, 1977.

BECKER, Gary. Human capital: a theoretical and empirical analysis, with special reference to education. New York: NBER/Columbia University Press, 1964.

CARDOSO, Adalberto Moreira. Economia $x$ sociologia: eficiência ou democracia nas relações de trabalho. Dados, v.43, n.1, 2000.

CARRIERI, Alexandre; SARSUR, Amyra M. Percurso semântico do tema empregabilidade: um estudo de caso em uma empresa de telefonia. In: ENCONTRO NACIONAL DE PÓS-GRADUAÇÃO EM ADMINISTRAÇÃO- EnANPAD, 26, 2002, Salvador-BA. Anais... Rio de Janeiro: Anpad, 2002. 1 CD-ROM.

CIVELLI, Franco. Personal competencies, organizational competencies, and employability. Industrial and Commercial Training, Guilsborough, v.30, n.2, p.48-52, 1998.

DENZIN, Norman K. The research act: a theoretical introduction to sociological methods. 2.ed. Chicago: Aldine Publishing Company, 1978.

DESLANDES, Suely Ferreira; CRUZ NETO, Otávio; GOMES, Romeu. Pesquisa social: teoria, método e criatividade. 7.ed. Petrópolis: Vozes, 1997.

DOURADO, Débora; CARVALHO, Cristina. O que existe sob o plácido manto da qualidade de vida no trabalho? Revelações sobre seus recursos retóricos e seu modo de operação ideológica através de um caso ilustrativo. In: ENCONTRO NACIONAL DE GESTÃO DE PESSOAS E RELAÇÕES DE TRABALHO - EnGPR, 1, 2007, Natal-RN, Anais... Natal: ANPAD, 2007. 1 CD-ROM.

FLICK, Uwe. Triangulation revisited: strategy of validation or alternative? Journal for the Theory of Social Behaviour, v.22, n.2, p.175-197, 1992.

FREITAS, Alexandre B. Traços brasileiros para uma análise organizacional. In: MOTTA, F. P.; CALDAS, M. (Org.). Cultura organizacional e cultura brasileira. São Paulo: Atlas, 1997.

FREITAS, M. E. Contexto social e imaginário organizacional moderno. Revista de Administração de Empresas, n.2, p.6$15,2000$.

GAZIER, B. Employability: the complexity of a policy notion. In: WEINERT, P. et al (Ed.). Employability: from theory to practice. New York: Transaction Publishers, 2001.

GOMES, M. S. E. A. Empregabilidade nos tempos de reestruturação e flexibilização: trajetórias de trabalho e narrativas de ex-empregados do setor elétrico brasileiro. Tese (Doutorado) - Instituto de Filosofia e Ciências Sociais, UFRJ, Rio de Janeiro, Brasil, 2002.

GRANOVETTER, Mark. Economic action and social structure: the problem of embeddedness. American Journal of Sociology, v.91, n.3, p.481-510, 1985.

HELAL, Diogo Henrique. Flexibilização organizacional e empregabilidade individual: proposição de um modelo explicativo. Cadernos Ebape.BR, v.III, n.1, p.1-15, mar. 2005.

; NEVES, Jorge Alexandre; FERNANDES, Danielle Cireno. Empregabilidade gerencial no Brasil. RAC- Revista de Administração Contemporânea Eletrônica, v.1, n.2, art.1, maio/ago. 2007, p.1-19.

LAVINAS, Lena. Empregabilidade no Brasil: inflexões de gênero e diferenciais femininos. Rio de Janeiro: Ipea, set. 2001. p.1-24 (Texto para discussão n.826).

MACHADO, Lucília. Educação básica, empregabilidade e competência. Trabalho \& Educação - Revista do Nete/UFMG, Belo Horizonte, n.3, p.15-31, jan./jul. 1998. 
MINARELLI, J. A. Empregabilidade: o caminho das pedras. São Paulo: Gente, 1995.

MINCER, Jacob. Schooling, experience, and earnings. New York: NBER/Columbia University Press, 1974.

NADER, Fernanda Milne-Jones; OLIVEIRA, Lúcia Barbosa. Empregabilidade: uma análise histórica e crítica. In: ENCONTRO NACIONAL DE PÓS-GRADUAÇÃO EM ADMINISTRAÇÃO - EnANPAD, 31, 2007, Rio de Janeiro-RJ, Anais... Rio de Janeiro: Anpad, 2007. 1 CD-ROM.

PAIVA, Vanilda. Qualificação, crise do trabalho assalariado e exclusão social. In: GENTILI, P.; FRIGOTTO, G. (Org.). A cidadania negada: políticas de exclusão na educação e no trabalho. 1.ed. Buenos Aires: Clacso, 2000. p.49-64.

PICCININI, Valmiria; OLIVEIRA, Sidnei. Flexibilização, qualidade de vida e empregabilidade: o caso das cooperativas de trabalho de Porto Alegre. In: ENCONTRO NACIONAL DE PÓS-GRADUAÇÃO EM ADMINISTRAÇÃO - EnANPAD, 26. 2002, Salvador-BA, Anais... Salvador: Anpad, 2002. 1 CD-ROM.

POCHMANN, Márcio. O emprego na globalização: a nova divisão internacional do trabalho. São Paulo: Ed. Boitempo, 2001.

RODRIGUES, José. Da teoria do capital humano à empregabilidade: um ensaio sobre as crises do capital e a educação brasileira. Trabalho \& Educação - Revista do NETE, Belo Horizonte, n.2, p.215-230, ago./dez. 1997.

RUMMERT, Sonia Maria; VENTURA, Jaqueline Pereira. Políticas públicas para educação de jovens e adultos no Brasil: a permanente (re)construção da subalternidade - considerações sobre os programas Brasil Alfabetizado e Fazendo Escola. Educar em Revista, n.29, p.29-45, 2007.

SCHULTZ, Theodore W. Investment in human capital. American Economic Review, v.51, p.1-17, Mar. 1961.

O capital humano: investimentos em educação e pesquisa. Rio de Janeiro: Zahar Editores, 1973.

SHIROMA, Eneida Oto; CAMPOS, Roselane Fátima. Qualificação e reestruturação produtiva: um balanço das pesquisas em educação. Educação \& Sociedade, v.18, n.61, p.13-35, dez. 1997.

THUROW, Lester. Education and Economic Equality. In: KARABEL, J., HALSEY, A. H. (eds.). Power and ideology in the education. New York: Oxford University Press, 1977.

ZULAUF, Monika. Ensino superior e desenvolvimento de habilidades para a empregabilidade: explorando a visão dos estudantes. Sociologias, n.16, p.126-155, dez. 2006. 